\title{
Hepatitis B Vaccination Status of Dentists and Their Approach to Hepatitis B Infected Patients - A Questionnaire Based Survey from Maharashtra
}

\author{
Sunil Suresh Kuyare ${ }^{1}$, Nanda G. Pai ${ }^{2}$, Ashwini A. Mankar³, Vidhi M. Makwana ${ }^{4}$, Gita Nataraj ${ }^{5}$ \\ 1, 3,5 Department of Microbiology, Seth GS Medical College and KEM Hospital, Parel, Mumbai, Maharashtra, India. \\ ${ }^{2,4}$ Department of Dentistry, Seth GS Medical College and KEM Hospital, Parel, Mumbai, Maharashtra, India.
}

\section{ABSTRACT}

\section{BACKGROUND}

Dentists are at high risk for Hepatitis B infection. Vaccination provides effective immunity. Not all dentists are vaccinated despite awareness and availability. Hepatitis B vaccination for health care workers is mandatory as per Biomedical Waste Management Rules, 2018. The present study was planned to determine the vaccination status amongst dentists and their approach to Hepatitis B infected patients.

\section{METHODS}

After the institutional ethics committee permission, the study was initiated. A Google form along with an online consent was emailed to all dentists registered with Maharashtra dental council (MDC). Post survey, a short information sheet was mailed to all, about the need for Hepatitis B vaccination and certain aspects related to it. The responses were automatically transferred to a Microsoft excel sheet and analyzed.

\section{RESULTS}

16,418 emails were sent out. 371 (2.3\%) participants responded, $352(2.1 \%)$ working dentists were included. $78.2 \%(\mathrm{~N}=273)$ were from urban area. $56 \%(\mathrm{~N}$ $=192$ ) participants were in the age group 22-30 years. Male to female ratio was $0.8: 1.52 .2 \%(\mathrm{~N}=184)$ had own clinic and $34.4 \%(\mathrm{~N}=121)$ were private practitioners. $56.4 \%(\mathrm{~N}=195)$ were dental graduates and $43.6 \%(\mathrm{~N}=151)$ were postgraduates. The vaccination status of dentists was found to be $74.7 \%(\mathrm{~N}=263)$. Only $22.1 \%(\mathrm{~N}=58)$ had tested for antibody titre against Hepatitis $\mathrm{B}, 55.7 \%(\mathrm{~N}=$ 196) dentists routinely carried out hepatitis B testing of their patients. If patients tested positive, $53.1 \%(\mathrm{~N}=187)$ provided dental care in their own clinic.

\section{CONCLUSIONS}

Improving the hepatitis B vaccination amongst dentists will improve their safety and reduce their fear of managing infected patients.

\section{KEY WORDS}

Hepatitis B, Vaccination, Dentists, Survey.
Corresponding Author:

Dr. Gita Nataraj,

Professor and HOD

$7^{\text {th }}$ Floor, Department of Microbiology,

Multi Storey Building, Seth GS Medical

College and KEM Hospital, Parel,

Mumbai-400012, Maharashtra, India.

E-mail: gitanataraj@gmail.com

DOI: $10.14260 /$ jemds $/ 2022 / 24$

How to Cite This Article:

Kuyare SS, Pai NG, Mankar AA, et al. Hepatitis $B$ vaccination status of dentists and their approach to hepatitis $B$ infected patients - a questionnaire based survey from Maharashtra. J Evolution Med Dent Sci 2022;11(01):126-131, DOI: $10.14260 / \mathrm{jemds} / 2022 / 24$

Submission 17-12-2021,

Peer Review 11-01-2022,

Acceptance 18-01-2022,

Published 28-01-2022.

Copyright (c) 2022 Sunil Suresh Kuyare et al. This is an open access article distributed under Creative Commons Attribution License [Attribution 4.0 International (CC BY 4.0)] 


\section{BACKGROUND}

Hepatitis B virus is transmitted by exposure to infectious blood and / body fluids. India is second to China in the number of people with chronic HBV infection. ${ }^{1,2}$ Of all the bloodborne disease transmission, Hepatitis $\mathrm{B}$ can be transmitted even with a minute quantity of blood exposure. ${ }^{2}$ Health Care Workers(HCW) are considered to be at high risk of exposure to this virus through exposure to blood or its products especially those from dental discipline. ${ }^{1,4}$ It is known that the hepatitis B virus is present in blood and body fluids but its presence in saliva cannot be ruled out. Hence, doctors in the dental discipline are exposed to blood (during the procedure) as well as saliva thus putting them in a high-risk category. Among blood-borne viruses, a prophylactic vaccine is available only for HBV. ${ }^{3}$ Post-vaccination, the protection is maintained for almost 30 years and above irrespective of anti-HBs antibody titre provided, there is demonstrable seroconversion. ${ }^{5}$ In spite of potential risks, a proportion of HCWs never get vaccinated. There is a need for all HCWs to undergo hepatitis B vaccination.6,7 Guidelines recommend three doses $(1 \mathrm{ml})$ taken at intervals of 0,1 and 6 months for adults. ${ }^{5}$ It is also recommended that two months postvaccination, especially for high-risk groups, the antibody titre should be checked to determine the protective efficacy of the vaccination. ${ }^{1,5,8}$ The knowledge about booster dose in regard to its necessity as well as its frequency also varies from doctor to doctor. Recent Biomedical Waste Management Rules published in March 2016 by the Ministry of Environment, Forests and Climate Change also mandates vaccination of all the HCWs. ${ }^{7}$

HBsAg prevalence among dentists is reported to be $2.4 \%$ in Malaysia, ${ }^{9} 13 \%$ in Korea ${ }^{10}$ while that reported in India is $32.02 \%{ }^{11}$ Studies show that HBV vaccination and the antiHBs antibody levels are not completely adequate among dentists despite being at risk of infection. ${ }^{2}$

As per WHO, in India, almost $4 \%$ general population could be infected with hepatitis B infection most of whom are asymptomatic. This raises a query about the approach of the dentists during the management of patients visiting for dental procedures who may be asymptomatic carriers of hepatitis B infection. In view of the high risk of hepatitis B infection to dentists and stigma attached to hepatitis B infected patients, the present study was conducted to determine the vaccination status amongst dentists all over Maharashtra, their suggestions to improve the vaccination coverage and their approach to hepatitis B infected patients.

\section{METHODS}

This was a cross-sectional, pre-validated questionnaire-based study that was carried out amongst dentists and dental specialists located all over Maharashtra. The list of all the dentists and dental specialists was collected from Maharashtra State Dental Council [MSDC]. The study was carried out for a period of 6 months i.e. from July 2017 to December 2017.

Institutional ethics committee permission was sought before the initiation of the study (EC/OA99/2017). A short online consent form which was approved by the committee was sent via email. This was accompanied by a questionnaire (as a Google form) to the participants expressing voluntary participation. Those who were willing to volunteer were requested to complete the questionnaire.

\section{Study Participants and Study Procedure}

To practice in the field of dentistry within Maharashtra, all dental practitioners must register under MSDC. A letter of request was submitted to MSDC for sharing the email addresses of the registered dental practitioners. Dentists whose email addresses were available with MSDC were included in the present study. On receipt of the email addresses, individual emails were sent to different dentists so that the confidentiality of each doctor was strictly maintained. This email included a summary of the study and an online consent form along with the link for the questionnaire. For voluntary participation, a sentence was included stating that if you do not wish to participate, you may not fill out the questionnaire. In case the participants agreed, the questionnaire was filled and submitted, which was automatically transferred to the Google excel sheet. The participants were also informed about their right not to answer any question if they found it uncomfortable to do so. A reminder was also sent once to those who did not respond.

\section{Questionnaire}

Questionnaire as Google form was considered as an easy tool to approach a large number of dentists in the state of Maharashtra. This questionnaire was validated by experts ( $\mathrm{N}$ $=5$ ) in the field of Hepatitis $\mathrm{B}$ which included $\mathrm{a}$ microbiologist, a clinician, a dentist and a gastroenterologist.

\section{The Questionnaire had Three Themes and Six Sections. \\ Theme 1 (Section 1): Demographic Data and General Information}

Details of participants such as their address, rural/urban area, age, gender, educational qualification, clinical practice area, years of experience in dental discipline were included.

Theme 2 (Section 2-5): Vaccination Status and Their Approach to Hepatitis B Infected Patients This theme covered the vaccination status of dentists and their approach to hepatitis B infection such as preoperative hepatitis B testing, providing dental treatment to patients (if positive) and their view about recommending hepatitis $B$ vaccination to patients. Information on complete/ incomplete vaccination courses was also recorded. For those who had completed their vaccination course, information on details of vaccination, booster doses and anti-HBs titres were included.

For those who did not complete their vaccination course or did not know their vaccination status or were not vaccinated, information as applicable on the number of doses taken, the reason for not completing vaccination course or not taking the vaccine, their interest in re-vaccination and details about anti-HBs antibody titres were included.

Theme 3 (Section 6): Suggestions

Dentists were also invited to provide suggestions to improve acceptance of hepatitis B vaccination and determine antibody titre (Anti HBs) post-vaccination. 


\section{Sample Size}

It was decided to include all dental practitioners who were registered with MSDC

\section{Statistical Analysis}

The results were analyzed using the chi-square test. The calculations were carried out in numbers and percentages.

\section{RESULTS}

A list of 19,166 dentists registered with MSDC as of 31.3.2017 was received. Email addresses of 17,270 dentists were available and emails were sent to these dentists of which 852 emails bounced while 16,418 of them received the email.

A total of 270 dental practitioners (1.6\%) responded within 4 months. A reminder email was sent after a gap of 4 months and an additional 101 responses (0.6\%) were received. Thus a total of 371 participants $(2.3 \%)$ responded.

Of the 371 participants who responded, 19 (5.1\%) were not practising and hence were not included for further analysis. Of the 352, 158 were men and 194 were women with men to women ratio of $0.8: 1$. Of 343 participants whose age was mentioned, 192 belonged to the age group of 22 to 30 years, followed by 31 to 40 years $(\mathrm{N}=102)$. The remaining 32 and 17 were from the age group of 41 to 50 years and more than 50 years respectively.

349 participants responded about their area of stay of which 273 were from urban area, 51 from semi-urban and 25 from rural areas. The professional qualifications of the participants ( $\mathrm{N}=346$ responses) were BDS (195), MDS (25), Oral maxillofacial surgeons (31), Endodontists (22), Orthodontists (20), Pedodontists (14), Periodontists (15), Prosthodontists (9), Community dentistry (6), Oral Pathologists (5) and Oral radiologists (4).

Most of the participants had their clinic [184; $52.2 \%]$ $34.4 \%(\mathrm{~N}=121)$ worked in a private hospital, $9.1 \%$ were in government service and $8 \%$ in semi-government service.

\section{Vaccination Status amongst Dental} Practitioners

A total of 263 participants $(74.7 \%)$ had taken a complete course of hepatitis B vaccination whereas 46 (13.1\%) and 26 (7.4\%) had either taken incomplete vaccination or not taken vaccine respectively. Seventeen participants $(4.8 \%)$ did not know their vaccination status.

Of 263 completely vaccinated dentists, 162 (61.6\%) had taken booster dose/s varying from one dose to six doses. 58 participants $(22.1 \%)$ tested for antibody titre postvaccination.

Of 221 responses received about the reason for uptake and completion of hepatitis $B$ vaccination course, knowledge/awareness [81; $36.7 \%$ ] was the commonest reason followed by mandatory vaccination [54; $24.4 \%$ ], being inspired by others [40; $18.1 \%]$, risk of health/disease [34; $15.4 \%]$ and vaccination in camps [12; $5.4 \%]$.

Of the 46 participants who were incompletely vaccinated or did not remember their vaccination status, 14 had taken only one dose while 32 had taken two doses of hepatitis B vaccination course. The commonest reasons for not completing the vaccination course were forgetfulness (21), negligence (5), insufficient knowledge (3), laziness (1), accident (1) and others (4). Of these, 38 (82.5\%) were eager to restart and complete the course of vaccination.

26 participants did not receive hepatitis B vaccination. The reasons were ignorance, non-availability and apprehension about allergic reaction. Of these, 24 (92.3\%) were willing to initiate a revaccination course.

\section{Willingness to Vaccination}

When asked about their willingness to initiate a revaccination course, $82.6 \%(38 / 46)$ from the incomplete vaccination group and $92.3 \%(24 / 26)$ from the non-vaccinated group agreed.

\section{Attitude of Dentists towards Known Hepatitis B Infected Patients}

As per the response received $(\mathrm{N}=352), 196$ dental practitioners $(55.7 \%$ ) carried out preoperative hepatitis $\mathrm{B}$ testing of their patients. 187 (53.1\%) practitioners provided treatment to hepatitis B infected patients whereas 54 (15.3 $\%)$ stated that they preferred a switch to conservative treatment, $79(22.4 \%)$ referred to government hospitals or other private clinics. 261/352 (74.1\%) recommended hepatitis $B$ vaccination to their patients.

Comparison between dentists as per gender, age and area of working are presented in Table 1, 2 and 3 respectively.

\section{Suggestions Provided to Improve the Vaccinations Status}

One or more suggestions were received from 237 dental practitioners for improving the vaccination uptake. The most common suggestion provided was mandatory vaccination $(\mathrm{N}=108)$ followed by awareness $(\mathrm{N}=106)$ and organizing camps $(\mathrm{N}=28)$.

11 participants stated that this survey would make HCWs conscious about keeping themselves healthy while treating patients.

\begin{tabular}{|c|c|c|c|c|c|c|}
\hline & & \multicolumn{4}{|c|}{ Men $(\mathrm{N}=158)$ Women $(\mathrm{N}=194)$} & \multirow{2}{*}{$\begin{array}{c}\text { P } \\
\text { Value }\end{array}$} \\
\hline & & $\mathbf{N}$ & $\%$ & $\mathbf{N}$ & $\%$ & \\
\hline \multirow{3}{*}{$\begin{array}{l}\text { Vaccination } \\
\text { details }\end{array}$} & Vaccination status & 120 & 75.9 & 143 & 73.7 & 0.721 \\
\hline & Booster dose taken & 75 & 62.5 & 87 & 60.8 & 0.882 \\
\hline & Antibody titre tested & 28 & 23.3 & 30 & 21.0 & 0.757 \\
\hline \multirow{3}{*}{ Practice } & Preop Hepatitis B testing & 78 & 49.4 & 118 & 60.8 & 0.041 \\
\hline & $\begin{array}{l}\text { Treat patients if HBV } \\
\text { positive }\end{array}$ & 92 & 58.2 & 95 & 49.0 & 0.104 \\
\hline & $\begin{array}{c}\text { Recommend vaccination } \\
\text { to patients }\end{array}$ & 119 & 75.3 & 142 & 73.2 & 0.742 \\
\hline & le 1. Hepatitis B Vacci & 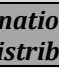 & $\begin{array}{l}\text { nd } P r \\
\text { on }\end{array}$ & $\theta$ & & \\
\hline
\end{tabular}

\begin{tabular}{|c|c|c|c|c|c|c|c|c|}
\hline & & \multicolumn{2}{|c|}{$\begin{array}{l}<30 \text { yrs } \\
(N=192)\end{array}$} & \multicolumn{2}{|c|}{$\begin{array}{c}31-40 \text { yrs } \\
(\mathrm{N}=102)\end{array}$} & \multicolumn{2}{|c|}{$\begin{array}{l}>40 \text { yrs } \\
(N=49)\end{array}$} & \multirow{2}{*}{$\begin{array}{c}P \\
\text { Value }\end{array}$} \\
\hline & & N & $\%$ & $\mathbf{N}$ & $\%$ & $\mathbf{N}$ & $\%$ & \\
\hline \multirow{3}{*}{$\begin{array}{l}\text { Vaccinati } \\
\text { on details }\end{array}$} & $\begin{array}{l}\text { Vaccination } \\
\text { status }\end{array}$ & 138 & 71.9 & 78 & 76.5 & 43 & 87.8 & 0.067 \\
\hline & $\begin{array}{l}\text { Booster dose } \\
\text { taken }\end{array}$ & 89 & 64.5 & 40 & 22.5 & 31 & 72.1 & 0.050 \\
\hline & $\begin{array}{l}\text { Antibody titre } \\
\text { tested }\end{array}$ & 21 & 15.2 & 24 & 13.5 & 12 & 27.9 & 0.018 \\
\hline \multirow{3}{*}{ Attitude } & $\begin{array}{l}\text { Preop Hepatitis B } \\
\text { testing }\end{array}$ & 110 & 57.3 & 56 & 54.9 & 25 & 51.0 & 0.720 \\
\hline & $\begin{array}{l}\text { Treat patients if } \\
\text { HBV positive }\end{array}$ & 98 & 51.0 & 53 & 52.0 & 30 & 61.2 & 0.436 \\
\hline & $\begin{array}{l}\text { Recommend } \\
\text { vaccination to } \\
\text { patients }\end{array}$ & 149 & 77.6 & 72 & 70.6 & 33 & 67.3 & 0.218 \\
\hline \multicolumn{9}{|c|}{ Table 2. Hepatitis B Vaccination and Practice - Age Wise } \\
\hline
\end{tabular}




\begin{tabular}{|c|c|c|c|c|c|c|c|c|}
\hline & & \multicolumn{2}{|c|}{ Urban (273) } & \multicolumn{2}{|c|}{$\begin{array}{c}\text { Semi-urban } \\
\text { (51) }\end{array}$} & \multicolumn{2}{|c|}{ Rural (25) } & \multirow{2}{*}{$\begin{array}{c}\text { P } \\
\text { Value }\end{array}$} \\
\hline & & $\mathbf{N}$ & $\%$ & $\mathbf{N}$ & $\%$ & $\mathbf{N}$ & $\%$ & \\
\hline \multirow{3}{*}{$\begin{array}{l}\text { Vaccination } \\
\text { details }\end{array}$} & $\begin{array}{l}\text { Vaccination } \\
\text { status }\end{array}$ & 213 & 78.0 & 40 & 78.4 & 19 & 76 & 0.969 \\
\hline & $\begin{array}{l}\text { Booster dose } \\
\text { taken }\end{array}$ & 135 & 67.2 & 19 & 47.5 & 14 & 73.7 & 0.090 \\
\hline & $\begin{array}{l}\text { Antibody titre } \\
\text { tested }\end{array}$ & 50 & 24.9 & 7 & 17.5 & 4 & 21.1 & 0.700 \\
\hline \multirow{3}{*}{ Attitude } & $\begin{array}{l}\text { Preop Hepatitis } \\
\text { B testing }\end{array}$ & 164 & 60.1 & 25 & 49.0 & 15 & 60 & 0.339 \\
\hline & $\begin{array}{l}\text { Treat patients if } \\
\text { HBV positive }\end{array}$ & 159 & 58.2 & 24 & 47.1 & 10 & 40 & 0.095 \\
\hline & $\begin{array}{l}\text { Recommend } \\
\text { vaccination to } \\
\text { patients }\end{array}$ & 201 & 73.6 & 41 & 80.4 & 18 & 72 & 0.570 \\
\hline
\end{tabular}

\section{DISCUSSION}

The present study is a unique online survey done to reach out to more than 16,000 dentists located in different parts of Maharashtra not only to find out about their hepatitis B vaccination status but also about their approach to hepatitis B infection while dealing with patients.

A Google form was used as it is an easy and unique way for communicating with a large number of persons with the response being directly transferred in the Google worksheet thereby facilitating analysis. Google forms have been used in other studies also. ${ }^{12,13}$

The cumulative response to the online survey even after reminder emails was low $(2.3 \%)$ as compared to other studies which varied from $8.2 \%$ to $66 \%{ }^{14-17}$ The reasons could be a busy practice, no personal benefit or the number of emails received from various sites making the participant less likely to respond to such emails sent by persons not directly known to them. Dunn et al. have suggested that a reminder email be sent after one month ${ }^{18}$ while in our case, even after a reminder email sent after four months, an additional response of $0.6 \%$ was only achieved.

The authors believe that this response rate could have been increased if dental associations/ authorities had actively participated by posting notices on their website or any other means. ${ }^{19}$ This would have then helped to generate actual vaccination status amongst dentists and thereby give a better understanding of their vaccination status. Yau et al. successfully carried out a telephonic survey through an external company and completed the survey in more than 1000 persons in the community. ${ }^{20}$ These kind of options need to be considered in future studies.

However, for a mass population where direct contact is not possible, email surveys can still be considered as the best approach even when the response rate is low.

Dunn et al. have reported that the reliability of such a response is questionable. ${ }^{18}$ Considering the categories of responders (dentists) and the topic under study, it can be stated that the response can be considered reliable.

$5 \%$ of dentists in the age group of 22 to 30 years were not practising of which $84 \%$ were women. Apart from BDS and MDS qualifications, nine different specialists too participated in the survey.

\section{Vaccination Status}

The vaccination rate for Hepatitis $\mathrm{B}$ amongst dentists in Maharashtra was found to be $74.7 \% .20 .5 \%$ had either not completed the vaccination series or were non-vaccinated. This is a cause of concern. The vaccination status amongst dentists in India varies geographically. Studies from north and Mysore city report a vaccination status of $52 \%$ to 59.5 $\%,{ }^{21,22}$ Agra $(82 \%)^{23}$ and $85.4 \% .{ }^{4}$

There were no studies from the western part of India about the vaccination status amongst dentists. Our state has better vaccination status but less as compared to vaccination coverage in other countries which ranges from $63.3 \%$ to 100 $\% .{ }^{17,24}$ Although multiple studies report vaccination status amongst dental students who will surely be future dental practitioners, there is a need to focus on those who are already practising and are not vaccinated. As per CDC guidelines/WHO position paper, incomplete vaccination is more dangerous as the HCWs are in a false notion of being protected.8,25 Thus, completing the vaccination course is mandatory for providing effective protection.

Considering that India belongs to intermediate to high endemicity with the prevalence of approximately $11 \%,{ }^{26}$ it becomes the responsibility of the authorities/councils to take necessary steps to vaccinate all dentists at the state level as well as country level.

In the present study, $61.6 \%$ of dentists took booster dose/s varying from one dose to six doses and 58 participants $(22.1 \%)$ tested for post-vaccination antibody titres which was lower as compared to other study where $70.9 \%$ tested for antibody titre. ${ }^{17}$

As per the WHO position paper, there is no need for booster dose but testing for post-vaccination anti-HBs antibody titre is recommended for HCWs. ${ }^{25}$ There is a need to create awareness amongst dentists to complete the vaccination course once and inform them that booster dose is not required.

Dentists considered that knowledge/awareness [81; 36.7 \%] was the commonest factor for uptake of vaccination followed by a policy of mandatory vaccination [54; $24.4 \%$ ]. The regulatory authorities should therefore take steps to create awareness amongst all HCWs about the need for the vaccination and make hepatitis $B$ vaccination mandatory for continuing the registration process thereby protecting the dental discipline or other HCWs.

Dentists and other HCWs are adults and therefore do not have a frequent vaccination schedule as infants do. The commonest reason mentioned for incomplete vaccination was forgetfulness. ${ }^{21}$ Any program targeting hepatitis B vaccination should not only initiate vaccination amongst the dentists but also ensure completeness of the vaccine series. This can be overcome by computer software which can send frequent timed reminders. A software for hepatitis B vaccination reminder was created by the hospital infection control committee (HICC) of our institute which served well and should be built-in into any hepatitis B vaccination series. The same software was used for the hepatitis $\mathrm{B}$ vaccination drive thereby reducing the dropout rate from $18 \%$ to $2 \%$. (Unpublished data) 


\section{Attitude of Dentists towards Known Hepatitis B Infected Patients}

Our study shows that 196 dentists (55.7\%) carried out preoperative hepatitis B testing and 187 (53.1 \%) dentists treated the patients even if hepatitis B infection was detected. Other studies 27,28 also suggested an unwillingness amongst the practitioners to treat hepatitis B infected patients (55\% and $32 \%$ ). Kohli et al. have suggested that every person is to be considered positive and treatment offered. ${ }^{29}$ The regulatory authorities need to look into how this discrimination can be reduced.

In the present study, male dentists agreed to treat infected patients more as compared to women dentists (Table 1) which is similar to the findings by Mahboobi et al. ${ }^{24}$

An age-based analysis showed that older dentists agreed to treat positive patients compared to the younger dentists (Table 2). However, younger dentists motivated the patients for hepatitis B vaccination.

\section{Suggestion for Improving Vaccination Status amongst Dentists}

The most common suggestion provided was mandatory vaccination $(\mathrm{N}=108)$ followed by creating awareness $(\mathrm{N}=$ 106) and organizing camps $(\mathrm{N}=28)$. Bedi et al. also suggested formulating a policy in India for the same. ${ }^{30}$ Kohli et al. have described in detail the infection control in dental settings including the coverage of hepatitis $B$ vaccination and have proposed mandatory vaccination for all dentists. ${ }^{29}$

The state dental council or Dental Council of India needs to make this vaccination mandatory during the renewal of registration. This will help improve hepatitis $B$ vaccination coverage. Not only CDC and WHO but the recent Biomedical Waste Management Rules 2016 has also recommended mandatory vaccination for all HCWs which include dentists.7,8,25 However, to implement the same, it is necessary for the regulatory authorities to take active participation. ${ }^{24}$ The availability of email addresses with the MSDC is appreciative and can be utilized as a platform for not only vaccination status but also for further creating awareness as well as initiating the vaccination through reminder emails and other healthcare-related issues.

\section{CONCLUSIONS}

Considering that there are less data regarding the vaccination status amongst dentists and since dentists are at a higher risk of hepatitis B infection, a national level programme should be applied to this group of HCWs.

\section{Limitations \\ To reduce the length of the Google form questionnaire for better response, the questions about hepatitis B asked were limited. A reminder could have been sent after 15 days of the first email which could have increased the response rate. Further study using a mobile app for reminders may provide useful data for improving the response rate.}

Data sharing statement provided by the authors is available with the full text of this article at jemds.com.
Financial or other competing interests: None.

Disclosure forms provided by the authors are available with the full text of this article at jemds.com.

We would like to thank Maharashtra State Dental Council [MSDC] for providing the email addresses of dentists from all over Maharashtra registered under them without which the study could not have been possible.

\section{REFERENCES}

[1] Momeni N, Akhoundi MSA, Alavian SM, et al. HBV vaccination status and response to hepatitis $B$ vaccine among Iranian dentists, correlation with risk factors and preventive measures. Hepatitis Mon 2015;15(1):e20014.

[2] Sukriti, Pati NT, Sethi A, et al. Low levels of awareness, vaccine coverage, and the need for boosters among health care workers in tertiary care hospitals in India. J Gastroenterol Hepatol 2008;23(11):1710-5.

[3] Hofmann F, Kralj N. Criteria for successful hepatitis B vaccination in adults: results of a case study. Infection 2009;37(3):266-9.

[4] Reddy V, Bennadi D, Kshetrimayum N, et al. Prevalence of hepatitis $\mathrm{B}$ vaccination among oral health care personnel in Mysore city, India. Oral Health Dent Manag 2014;13(3):652-5.

[5] Janes J. Survey research design. Library Hi Tech 2001;19:419-21.

[6] US Public Health Service. Updated US Public Health Service Guidelines for the management of occupational exposures to HBV, HCV, and HIV and recommendations for postexposure prophylaxis. MMWR. Recommendations and reports: morbidity and mortality weekly report. Recommendations and reports 2001;50:1.

[7] Government of India, Ministry of Environment, forests and climate change. Bio-Medical waste management rules. Gazette of India. 2016 March. http://mpcb.gov.in/biomedical/pdf/BMW_Rules_2016.p df

[8] Schillie S, Murphy TV, Sawyer M, et al. CDC guidance for evaluating health-care personnel for hepatitis B virus protection and for administering postexposure management. MMWR Recomm Rep 2013;62(RR-10):119.

[9] Vadivale M, Tan TC, Ong CN. Sero-prevalence of hepatitis B infection among dental professionals. Singapore Med J 1992;33(4):367-9.

[10] Song KB, Choi KS, Lang WP, et al. Hepatitis B prevalence and infection control among dental health care workers in a community in South Korea. J Public Health Dent 1999;59(1):39-43.

[11] Chobe LP, Chadha MS, Arankalle VA, et al. Hepatitis B infection among dental personnel in Pune \& Bombay (India). Indian J Med Res 1991;93:143-6.

[12] Ramachandran S, Carounanidy U, Manikandan S, et al. Evaluation of knowledge, attitude, and practices about the health-related occupational hazards among dental practitioners in Pondicherry, India. J Educ Ethics Dent 2017;7(2):44-8.

[13] Patel H, Mehta K. Perception of dental professionals of Gujarat on their role in deaddiction services. Universal Research Journal of Dentistry 2016;6(2):119-22. 
[14] Dannetun E, Tegnell A, Giesecke J. Parents' attitudes towards hepatitis B vaccination for their children. A survey comparing paper and web questionnaires, Sweden 2005. BMC Public Health 2007;7(1):86.

[15] Raghavan S, Dayal P, Philip K, et al. Dentists' attitudes and perceptions toward protective mouthguards. Niger J Clin Pract 2018;21(3):318-26.

[16] Kelkar AS, Chang DF, Kelkar JA, et al. Antibiotic prophylaxis practice patterns for cataract surgery in India-Results from an online survey. Indian J Ophthalmol 2017;65(12):1470-4.

[17] McCarthy GM, Koval JJ, MacDonald JK. Occupational injuries and exposures among Canadian dentists: the results of a national survey. Infect Control Hosp Epidemiol 1999;20(5):331-6.

[18] Dunn KA, Huss HF. Mail survey reliability through follow-up mailings: the case of auditor changes. Managerial Auditing Journal 2004;19(8):1048-54.

[19] Laramie AK, Bednarsh $H$, Isman $B$, et al. Use of bloodborne pathogens exposure control plans in private dental practices: results and clinical implications of a national survey. Compend Contin Educ Dent 2016;38(6):398-407.

[20] Yau AHL, Ford JA, Kwan PWC, et al. Hepatitis B awareness and knowledge in Asian communities in British Columbia. Can J Gastroenterol Hepatol 2016;2016:4278724.

[21] Kardam P, Mehendiratta M, Rehani S, et al. Seroprevalence and vaccination status of hepatitis $B$ amongst dental health-care workers in North India. Indian J Gastroenterol 2014;33(2):190-1.
[22] Singhal V, Bora D, Singh S. Hepatitis B in health care workers: Indian scenario. J Lab Physicians 2009;1(2):418.

[23] Dubey HV, Ingle NA, Kaur N, et al. Knowledge, attitude and practice towards personal protective measures adapted by dental practitioners in Agra city - a cross infection control measure. Journal of Oral Health \& Community Dentistry 2014;8(3):128-30.

[24] Mahboobi N, Agha-Hosseini F, Mahboobi N, et al. Hepatitis B virus infection in dentistry: a forgotten topic. J Viral Hepatitis 2010;17(5):307-16.

[25] Hepatitis B vaccines: WHO position paper, July 2017, Weekly epidemiological record No. 27, 2017:369-92.

[26] Lahariya C, Subramanya BP, Sosler S. An assessment of hepatitis B vaccine introduction in India: lessons for roll out and scale up of new vaccines in immunization programs. Indian Journal of Public Health 2013;57(1):814.

[27] El-Maaytah MA, Jerjes W, Upile T, et al. Willingness of Jordanian clinicians to treat a hepatitis B-infected patient. Quintessence Int 2008;39(4):e147-51.

[28] Alavian SM, Mousavi SH, Azizi B, et al. Study of admission rate of hepatitis $B$ surface antigen positive patients in 50 dentistry centers in Tehran (Spring 2003). Hepat Mon 2008;8(1):67-9.

[29] Kohli A, Puttaiah R, Bedi R, et al. Infection control \& occupational safety recommendations for oral health professionals in India 2007.

[30] Bedi R. Changing patient safety in India: Mandatory hepatitis B immunity. Contemp Clin Dent 2015;6(1):1-2. 